\title{
PENGARUH VARIASI MUKA AIR TANAH PADA TIMBUNAN DENGAN PERKUATAN GEOSINTETIK, SHEAR KEY, DAN TIANG PANCANG DI ATAS TANAH LUNAK
}

\author{
Abdurrahman Zuhri ${ }^{1}$, Bambang Setiawan ${ }^{2}$, Noegroho Djarwanti ${ }^{3}$ \\ ${ }^{1}$ Mahasiswa Program Studi Teknik Sipil, Universitas Sebelas Maret Surakarta \\ 2,3Dosen KBK Geoteknik, Program Studi Teknik Sipil, Universitas Sebelas Maret Surakarta \\ J1. Ir. Sutami No.36 A, Jebres, Surakarta 57126; Telp. 0271-634524 \\ Email : abdur.zuhri@gmail.com
}

\begin{abstract}
Soft soil has very low bearing capacity characteristics, besides the compressibility value is quite high and the consolidation time occurs in a very long time. The use of geosynthetic reinforcement, shear key, and pile functions to increase the stability of the embankment on soft soil. Water is the main factor that is very influential on soft soils. The difference in the depth of the ground water level has an effect on the stability of the embankment that has been given reinforcement. The results of this study indicate that the use of geosynthetic reinforcement, shear key, and pile will increase the stability of the embankment on soft soil, in the order of the increase in SF value of the model without reinforcement from the highest to the lowest, i.e: pile, geosynthetic, and shear key. The higher the ground water level elevation, the smaller the SF value generated. The average decrease in SF value against ground water level elevation increases from the largest to the smallest in a row, i.e: pile, geosynthetic, and shear key.
\end{abstract}

Keywords: soft soil, ground water level, geosynthetic, shear key, pile

\begin{abstract}
Abstrak
Tanah lunak memiliki karakteristik daya dukung yang sangat rendah, selain itu nilai kompresibilitasnya cukup tinggi dan waktu konsolidasi terjadi dalam waktu yang sangat lama. Penggunaan perkuatan geosintetik, shear key, dan tiang pancang berfungsi untuk meningkatkan stabilitas timbunan di atas tanah lunak. Air menjadi faktor utama yang sangat berpengaruh pada tanah lunak. Perbedaan kedalaman muka air tanah (MAT) memiliki pengaruh terhadap kestabilan timbunan yang telah diberi perkuatan. Hasil penelitian ini menunjukkan bahwa penggunaan perkuatan geosintetik, shear key, dan tiang pancang akan meningkatkan stabilitas timbunan di atas tanah lunak, dengan urutan kenaikan nilai SF terhadap model tanpa perkuatan dari tertinggi ke yang terendah berturut-turut yaitu: tiang pancang, geosintetik, dan shear key. Semakin tinggi elevasi MAT, nilai SF yang dihasilkan akan semakin kecil. Rata-rata penurunan nilai SF terhadap kenaikan elevasi MAT dari yang terbesar ke yang terkecil berturut-turut yaitu: tiang pancang, geosintetik, dan shear key.
\end{abstract}

Kata Kunci : tanah lunak, muka air tanah, geosintetik, shear key, tiang pancang

\section{PENDAHULUAN}

Terbatasnya lahan di bumi untuk pembangunan infrastruktur yang diperlukan manusia, mengakibatkan tidak dapat dihindarinya pembangunan di atas tanah yang kurang baik, misalnya adalah tanah lunak. Daya dukung tanah lunak sangat rendah, selain itu nilai kompresibilitasnya cukup tinggi dan waktu konsolidasi terjadi dalam waktu yang sangat lama. Sehingga, untuk dilakukannya konstruksi di atas tanah jenis ini, memerlukan metode khusus. Sebagai contoh adalah suatu pembangunan jalan tol di atas tanah lunak. Pada tahap awal konstruksi, dilakukan penimbunan di atas tanah asli. Pemberian timbunan tersebut dimaksudkan untuk mendapatkan elevasi jalan yang sesuai rencana. Akan tetapi, timbunan tersebut juga berdampak sebagai beban statis yang akan membebani tanah asli. Sehingga, tanah asli sendiri akan mengalami penurunan karena adanya konsolidasi.

Tanah timbunan yang dibangun di atas tanah lunak haruslah memiliki kekuatan dan stabilitas yang tinggi akibat pengaruh lingkungan terutama air untuk menopang beban kendaraan yang disalurkan dari perkerasan jalan. Tanah timbunan yang kekuatan dan stabilitasnya rendah akan mengakibatkan perkerasan di atasnya mudah mengalami kerusakan. Banyak metode perbaikan tanah yang dapat digunakan untuk meningkatkan stabilitas timbunan yang dibangun di atas tanah lunak, sebagai contoh adalah pemberian perkuatan geosintetik pada lapis timbunan, pemasangan shear key pada samping timbunan, dan pemasangan tiang pancang.

Pemberian perkuatan pada timbunan di atas tanah lunak tersebut tidak begitu saja membuat perkerasaan jalan yang dibangun di atasnya aman. Masih banyak faktor lain yang dapat mengganggu stabilitas timbunan di atas tanah lunak yang telah diberi perkuatan, misalnya adalah air. Tanah lunak akan mengalami perubahan volume ketika kadar air berubah. Pengurangan kadar air menyebabkan tanah lunak menyusut dan sebaliknya bila kadar air bertambah tanah 
lunak mengembang. Perbedaan kedalaman muka air tanah memiliki pengaruh terhadap kestabilan timbunan yang telah diberi perkuatan, sehingga diperlukan analisis khusus untuk mengetahui dampak yang akan terjadi.

\section{LANDASAN TEORI \\ Tanah Lunak}

Tanah lunak merupakan tanah yang memiliki karakteristik daya dukung yang rendah, selain itu nilai kompresibilitasnya cukup tinggi dan waktu konsolidasi terjadi dalam waktu yang sangat lama. Das (1995) mengatakan nilai hasil pengujian di lapangan dan di laboratorium, akan menunjukan bahwa tanah tersebut lunak apabila : Koefisien rembesan $(\mathrm{k})$ sangat rendah $\leq 0.0000001 \mathrm{~cm} / \mathrm{dt}$, batas cair $(\mathrm{LL}) \geq 50 \%$, angka pori (e) antara 2,5 - 3,2, kadar air dalam keadan jenuh antara 90\% - 120\%, dan berat spesifik (Gs) berkisar antara 2,6 - 2,9.

\section{Pengaruh Kedalaman MAT pada Tanah Lunak}

Tanah lunak sangat berpengaruh terhadap kadar air dalam tanah. Penambahan air pada tanah lunak menyebabkan pertambahan volume tanah lunak, sebaliknya pengurangan kadar air akan menyebabkan penurunan volume tanah lunak. Daud (2016) mengatakan pengaruh fluktuasi kadar air pada tanah dasar, yaitu: (1) Untuk tanah-tanah berpasir, sedikit fluktuasi kadar air hanya mengakibatkan sedikit perubahan volume dan kekuatan/kekakuan; (2) Untuk tanah-tanah berlanau, sedikit fluktuasi kadar air mengakibatkan sedikit perubahan volume, tapi dapat menghasilkan pengurangan kekuatan/kekakuan yang besar; (3) Untuk tanah lempung, sedikit fluktuasi kadar air dapat mengakibatkan perubahan volume yang besar, dan jika kadar air tanah mendekati kadar air optimum, maka perubahan kekuatan dan kekakuan yang signifikan akan terjadi.

\section{Metode Elemen Hingga}

Metode Elemen Hingga (MEH) atau biasanya disebut Finite Element Method (FEM) adalah prosedur numeris yang dapat dipakai untuk menyelsaikan masalah-masalah dalam bidang rekayasa (engineering), seperti analisa tegangan pada struktur, frekuensi pribadi dan mode shape-nya, perpindahaan panas, elektromagnetis, dan aliran fluida.

\section{Water Condition}

Water condition digunakan untuk memodelkan tinggi muka air tanah. Terdapat dua pilihan tipe pemodelan dalam program MEH, yaitu phreatic line dan ground water flow. Phreatic line digunakan dalam memodelkan kondisi hidrostatis, sedangkan ground water flow digunakan dalam memodelkan aliran air. Dalam penelitian ini digunakan model phreatic line.

\section{METODE}

Metode yang digunakan dalam penelitian ini adalah metode elemen hingga (MEH) pada pemodelan nonfisik dengan program MEH. Penelitian ini bersifat kuantitatif yaitu analisis pengaruh kedalaman MAT terhadap timbunan di atas tanah lunak yang telah diperkuat dengan geosintetik, shear key, dan tiang pancang. Pemodelan pada program MEH menggunakan model Mohr-Coulomb. Model Mohr-Coulomb adalah pemodelan tanah elastis plastis yang terdiri dari lima buah parameter, yaitu Modulus Young (E), Angka Poisson (v), sudut gesek dalam $(\varphi)$, kohesi $\left(c_{r e f}\right)$, dan sudut dilatasi $(\psi)$. Metode perhitungan yang digunakan dalam penelitian ini berupa consolidation dan $\mathrm{phi} / \mathrm{c}$ reduction dengan variabel penelitian adalah elevasi MAT pada tanah asli.

\section{Parameter Tanah}

Data parameter tanah diperlukan sebagai syarat input dalam pemodelan menggunakan program MEH. Adapun data parameter tanah yang digunakan disajikan dalam Tabel 1 berikut:

Tabel 1. Data parameter tanah pada input program MEH

\begin{tabular}{lccc}
\hline \multirow{2}{*}{ Parameter } & \multicolumn{2}{c}{ Nilai } & \multirow{2}{*}{ Satuan } \\
\cline { 2 - 3 } & Tanah Asli & Tanah Timbunan & \\
\hline Model material & Mohr-Coulomb & Mohr-Coulomb & - \\
\hline Perilaku material & Drained & Drained & - \\
\hline Berat isi tanah tidak jenuh $\left(\gamma_{\text {unsat }}\right)$ & 10,190 & 12,060 & $\mathrm{kN} / \mathrm{m}^{3}$ \\
\hline Berat isi tanah jenuh $\left(\gamma_{\text {sat }}\right)$ & 16,080 & 17,260 & $\mathrm{kN} / \mathrm{m}^{3}$ \\
\hline Permeabilitas horizontal $\left(k_{x}\right)$ & 0,042 & 0,007 & $\mathrm{~m} / \mathrm{hari}$ \\
\hline Permeabilitas vertikal $\left(k_{y}\right)$ & 0,042 & 0,007 & $\mathrm{~m} / \mathrm{hari}$ \\
\hline Modulus Young $\left(E_{r e f}\right)$ & 3922,660 & 73549,870 & $\mathrm{kN} / \mathrm{m}^{3}$ \\
\hline \hline
\end{tabular}




\begin{tabular}{lccc}
\hline Angka Poisson $(v)$ & 0,400 & 0,300 & - \\
\hline Kohesi $\left(c_{\text {ref }}\right)$ & 11,770 & 3,920 & $\mathrm{kN} / \mathrm{m}^{2}$ \\
\hline Sudut gesek dalam $(\varphi)$ & 4 & 28 & ${ }^{\circ}$ \\
\hline Sudut dilatasi $(\psi)$ & - & - & ${ }^{\circ}$ \\
\hline
\end{tabular}

\section{Parameter Perkerasan Jalan}

Material perkerasan jalan yang digunakan berupa pelat beton. Adapun data material perkerasan jalan yang digunakan ditunjukan oleh Tabel 2 berikut:

Tabel 2. Data parameter perkerasan jalan pada input program MEH

\begin{tabular}{lccc}
\hline \multicolumn{1}{c}{ Parameter } & Perkerasan Jalan & Median Jalan & Satuan \\
\hline Mutu beton $\left(f^{\prime} c\right)$ & 35 & 20 & $\mathrm{Mpa}$ \\
\hline Kekakuan $(E A)$ & 8341672,490 & 6305711,680 & $\mathrm{kN} / \mathrm{m}$ \\
\hline Kekakuan lentur $(E I)$ & 62562,540 & 47292,840 & $\mathrm{kNm} / \mathrm{m}$ \\
\hline Ketebalan $(d)$ & 0,300 & 0,300 & $\mathrm{~m}$ \\
\hline Berat pelat beton $(w)$ & 7,060 & 7,060 & $\mathrm{kN} / \mathrm{m} / \mathrm{m}$ \\
\hline Angka Poisson $(v)$ & 0,150 & 0,150 & - \\
\hline
\end{tabular}

\section{Data Pembebanan}

Tipe jalan yang digunakan dalam penelitian ini menggunakan tipe jalan arteri kelas IA dengan beban muatan sumbu terberat (MST) sebesar 10 ton (Rancangan Standar Nasional Indonesia tahun 2004 (RSNI T-14-2004) dan Binamarga tahun 1987). Beban overload ditentukan sebesar 20\% atau sebesar 2 ton. Sehingga beban total kendaraan adalah beban MST sebesar 10 ton ditambah beban overload sebesar 2 ton yaitu 12 ton dan didistribusikan kedalam setiap roda kendaraan pada ujung as sebesar 6 ton atau sama dengan $60 \mathrm{kN}$.

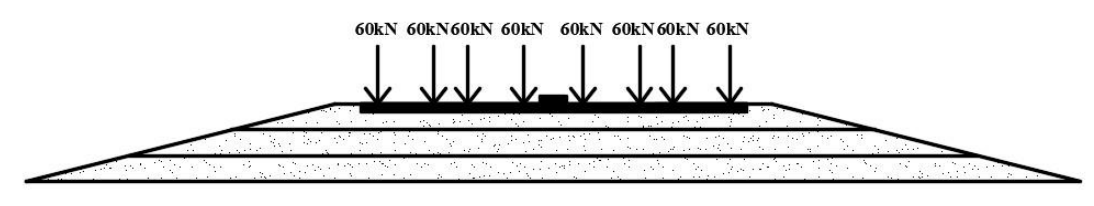

Gambar 1. Pemodelan pembebanan

\section{Variasi Kedalaman Muka Air Tanah (MAT)}

Penentuan variasi kedalaman MAT diambil setiap jarak $5 \mathrm{~m}$ dimulai dari dasar permukaan tanah asli yaitu elevasi $25,000 \mathrm{~m}$ hingga mencapai elevasi $0,000 \mathrm{~m}$ (permukaan tanah asli). Adapun variasi kedalaman MAT dalam penelitian ini yaitu: $-25,000 \mathrm{~m},-20,000 \mathrm{~m},-15,000 \mathrm{~m},-10,000 \mathrm{~m},-5,000 \mathrm{~m}$, dan $0,000 \mathrm{~m}$ (permukaan tanah asli).

\section{Pemodelan}

Model yang digunakan dalam penelitian ini berjumlah 4 model, yang meliputi: model tanpa perkuatan, model perkuatan geosintetik (Fitria Anggraeni, 2019), model perkuatan shear key (M. Indra Aji Kurniawan, 2019), dan model perkuatan tiang pancang (Muhammad Fathurahman, 2019). Model yang digunakan dalam penelitian ini ditampilkan pada Gambar 2 hingga Gambar 5 berikut:

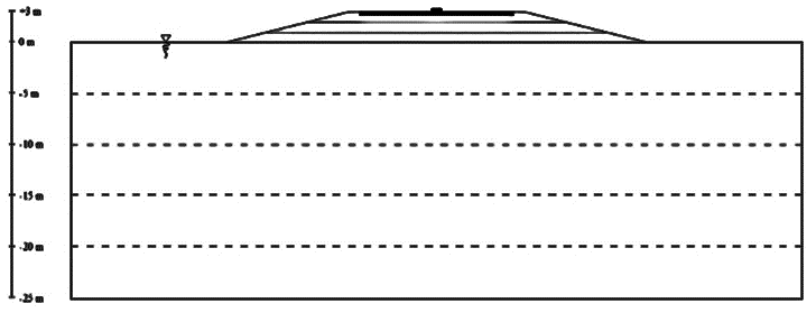

Gambar 2. Model Tanpa Perkuatan

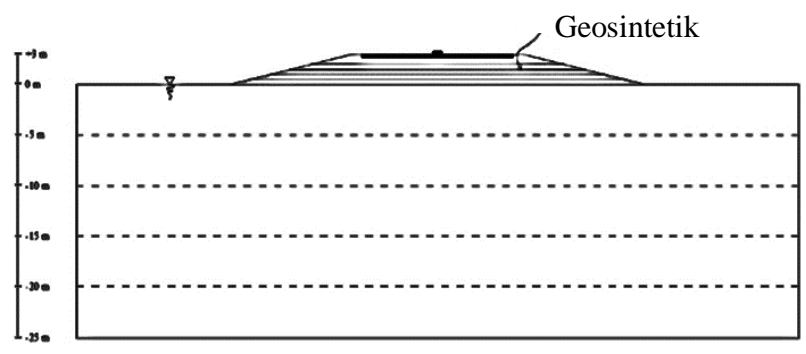

Gambar 3. Model Perkuatan Geosintetik 


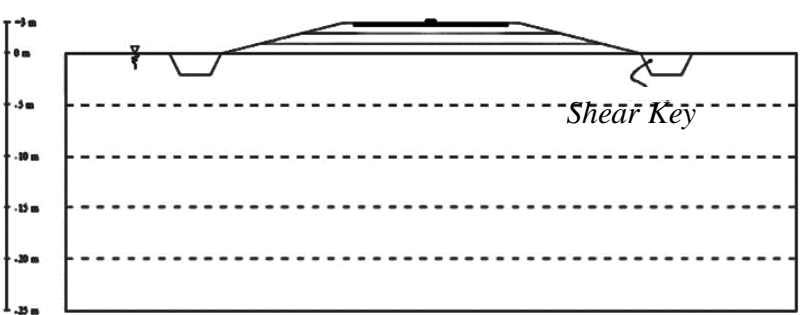

Gambar 4. Model Perkuatan Shear Key

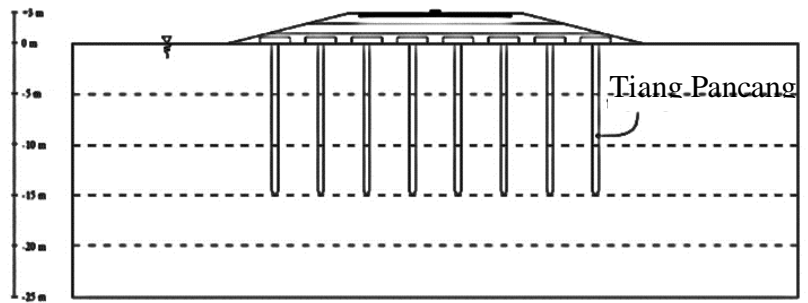

Gambar 5. Model Perkuatan Tiang Pancang

HASIL DAN PEMBAHASAN

Rekapitulasi Hasil Pemodelan

Berikut ini ditampilkan rekapitulasi nilai angka keamanan / safety factor (SF) hasil output pengaruh kedalaman MAT pada model tanpa perkuatan, model perkuatan geosintetik, shear key, dan tiang pancang dengan menggunakan program MEH. Hasil rekapitulasi nilai angka keamanan / safety factor (SF) disajikan dalam Tabel 3 berikut:

Tabel 3. Rekapitulasi hasil output pengaruh kedalaman MAT pada semua model menggunakan program MEH

\begin{tabular}{ccccc}
\hline \multirow{2}{*}{$\begin{array}{c}\text { Kedalaman MAT } \\
(\mathbf{m})\end{array}$} & \multicolumn{3}{c}{ Nilai Angka keamanan / Safety Factor (SF) } \\
\cline { 2 - 5 } & $\begin{array}{c}\text { Tanpa } \\
\text { Perkuatan }\end{array}$ & Geosintetik & Shear Key & $\begin{array}{c}\text { Tiang Pan- } \\
\text { cang }\end{array}$ \\
\hline 0,000 & 1,308 & 1,432 & 1,385 & 2,178 \\
\hline$-5,000$ & 1,380 & 1,515 & 1,469 & 2,258 \\
\hline$-10,000$ & 1,399 & 1,558 & 1,476 & 2,366 \\
\hline$-15,000$ & 1,396 & 1,562 & 1,474 & 2,452 \\
\hline$-20,000$ & 1,395 & 1,564 & 1,474 & 2,477 \\
\hline
\end{tabular}

\section{Angka keamanan / Safety Factor (SF)}

Grafik hubungan pengaruh kedalaman MAT terhadap nilai SF pada semua model ditampilkan pada Gambar 6 berikut:

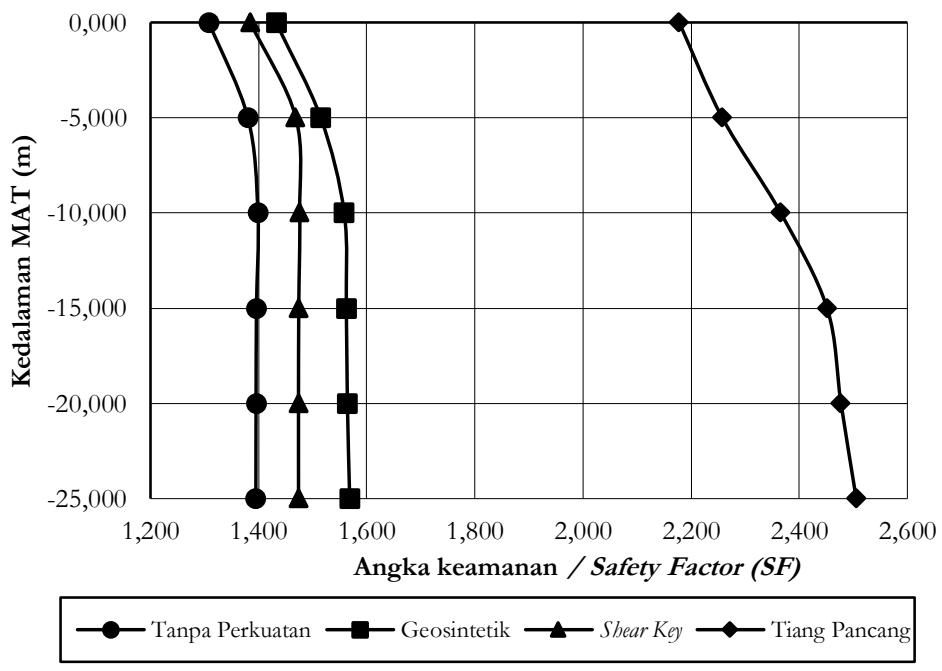

Gambar 6. Hubungan pengarub kedalaman MAT terhadap nilai SF pada semua model

Gambar 6 merupakan grafik perbandingan pengaruh kedalaman MAT terhadap nilai SF pada model perkuatan geosintetik, shear key, dan tiang pancang serta tanpa perkuatan. Grafik di atas menunjukkan kenaikan nilai SF pada model dengan perkuatan terhadap model tanpa perkuatan dengan urutan dari tertinggi ke yang terendah yaitu tiang pancang, geosintetik, dan shear key.

Nilai $S F$ yang terjadi pada model perkuatan tiang pancang saat elevasi MAT -25,000 m sebesar 2,505, dengan kenaikan nilai $S F$ terhadap model tanpa perkuatan sebesar 1,111 atau 79,61\%. Nilai $S F$ yang terjadi pada model perkuatan geosintetik dengan elevasi MAT yang sama yaitu sebesar 1,568, dengan kenaikan nilai $S F$ terhadap model tanpa perkuatan sebesar 0,174 atau 12,44\%. Nilai $S F$ yang terjadi pada model perkuatan shear key sebesar 1,474, dengan kenaikan nilai $S F$ terhadap model tanpa perkuatan sebesar 0,079 atau 5,66\%. 
Rata-rata penurunan nilai $S F$ terbesar terhadap kenaikan elevasi MAT terjadi pada model perkuatan tiang pancang dengan bentuk grafik paling landai jika dibandingkan dengan ketiga model lainnya, sedangkan rata-rata penurunan nilai $S F$ terkecil terjadi pada model perkuatan shear key. Rata-rata penurunan nilai SF terhadap kenaikan elevasi MAT pada semua model (tanpa perkuatan, geosintetik, shear key, dan tiang pancang) berturut-turut sebesar 0,017; 0,$027 ; 0,018 ;$ dan 0,065 .

Dari hasil di atas dapat disimpulkan bahwa semakin tinggi elevasi MAT maka nilai SF yang terjadi akan semakin kecil. Kenaikan nilai $S F$ yang terjadi pada model tanpa perkuatan dan model perkuatan shear key diduga dikarenakan oleh proses konsolidasi tanah asli (tanah lunak) yang masih berlangsung, sehingga selisih kenaikan nilai SF yang terjadi akibat konsolidasi lebih besar dari pada penurunan nilai $S F$ yang terjadi akibat kenaikan elevasi MAT.

Penurunan nilai $S F$ terbesar dari model tanpa perkuatan, geosintetik, dan shear key terjadi pada elevasi MAT -10,000 $\mathrm{m}$ hingga $0,000 \mathrm{~m}$ (permukaan tanah asli), hal tersebut terjadi karena elevasi MAT mencapai daerah distribusi deformasi yang berada pada kedalaman kurang lebih -10,000 $\mathrm{m}$ dari permukaan tanah asli, sedangkan pada model perkuatan tiang pancang, penurunan nilai $S F$ terbesar terjadi pada elevasi MAT -15,000 $\mathrm{m}$ hingga 0,000 $\mathrm{m}$, hal tersebut terjadi karena elevasi MAT mencapai dasar tiang pancang. Hal ini mengacu pada hasil penelitian Alwan (2010) yang mengatakan bahwa variasi kadar air mempengaruhi daya dukung pondasi tiang khususnya tipe friction pile, sehinggga semakin besar perubahan kadar air yang terjadi, semakin besar pula penurunan daya dukung ultimit tiang.

Dari pembahasan di atas disimpulkan bahwa kenaikan nilai $S F$ terbsesar terjadi pada model perkuatan tiang pancang sebesar 79,61\% terhadap model tanpa perkuatan, sedangkan kenaikan nilai $S F$ terkecil terjadi model perkuatan shear key sebesar 5,66\% dan model perkuatan geosintetik sebesar 12,44\%. Dilihat dari pengaruhnya terhadap kenaikan elevasi MAT, shear key menjadi model perkuatan dengan rata-rata penurunan nilai $S F$ terkecil dibandingkan dengan kedua model perkuatan lainnya yaitu sebesar 0,018, sedangkan rata-rata penurunan nilai $S F$ terbesar terjadi pada model perkuatan tiang pancang yaitu sebesar 0,065 dan model perkuatan geosintetik yaitu sebesar 0,027 .

\section{SIMPULAN}

Kenaikan nilai $S F$ terhadap penambahan perkuatan pada timbunan di atas tanah lunak terbesar terjadi pada model perkuatan tiang pancang sebesar 79,61\%, sedangkan kenaikan nilai $S F$ terkecil terjadi model perkuatan shear key sebesar $5,66 \%$ dan perkuatan geosintetik diantara keduanya yaitu sebesar $12,44 \%$.

Pengaruh kenaikan elevasi MAT terhadap nilai SF pada timbunan di atas tanah lunak yaitu semakin tinggi elevasi MAT maka nilai $S F$ yang terjadi akan semakin kecil. Rata-rata penurunan nilai $S F$ terkecil terhadap kenaikan elevasi MAT terjadi pada model perkuatan shear key sebesar 0,018; sedangkan rata-rata penurunan nilai $S F$ terbesar terjadi pada model perkuatan tiang pancang sebesar 0,065 dan perkuatan geosintetik diantara keduanya dengan rata-rata penurunan nilai $S F$ sebesar 0,027 .

\section{UCAPAN TERIMAKASIH}

Ucapan terimakasih kepada seluruh pihak yang telah membantu dalam penulisan artikel ini, dan juga kepada temanteman peminatan geoteknik 2015 yang telah memberikan motivasi semangat dan bantuan berupa ilmu untuk menambah wawasan berkaitan dengan artikel ini. Tak lupa juga kepada dosen pembimbing yang telah membimbing peneliti dalam menyelesaikan artikel ini.

\section{REFERENSI}

Alwan, I., dan Indarto, 2010. Pengarub Variasi Kadar Air terhadap Daya Dukung Pondasi Tiang Tipe Friction Pile pada Tanah Ekspansif, Jurusan Teknik Sipil, Institut Teknologi Sepuluh Nopember

Anggraeni, F., 2019. Pengaruh Variasi Lapis Geosintetik, terbadap Safety Factor Timbunan di atas Tanah Lunak, Teknik Sipil, Universitas Sebelas Maret

Das, B. M., 1995. Mekanika Tanah (Prinsip-Prinsip Rekayasa Geoteknis) Jilid I, Erlangga, Jakarta

Daud, D., D., A., A., 2016. Studi Pengarub Kualitas Lingkungan Geofisik Tanah terbadap Kerusakan Ruas Jalan Polisi Militer - Jalan Kejora, Program Pascasarjana, Universitas Gadjah Mada

Fathurahman, M., 2019. Pengarub Perkuatan Tiang pada Timbunan di atas Tanah Lunak menggunakan Metode Elemen Hingga, Teknik Sipil, Universitas Sebelas Maret 
Kurniawan, M. I. A., 2019. Pengaruh Perkuatan Shear Key terhadap Angka Keamanan dan Penurunan Maksimum pada Timbunan di atas Tanah Lunak, Teknik Sipil, Universitas Sebelas Maret

Laporan akhir penyelidikan tanah Kota Sidoarjo 